\title{
The hypoglycaemic and insulinotropic activity of Tinospora crispa: studies with human and rat islets and HIT-T15 B cells
}

\author{
H. Noor ${ }^{1}$, P. Hammonds ${ }^{1}{ }^{*}$, R. Sutton ${ }^{2}$ and S.J.H.Ashcroft ${ }^{1}$ \\ The Nuffield Departments of ${ }^{1}$ Clinical Biochemistry and ${ }^{2}$ Surgery, John Radcliffe Hospital, Headington, Oxford, UK
}

\begin{abstract}
Summary. In Malaysia, Tinospora crispa extract is taken orally by Type 2 (non-insulin-dependent) diabetic patients to treat hyperglycaemia. We have evaluated the claimed hypoglycaemic property by adding aqueous extract to the drinking water of normal and alloxan-diabetic rats. After one week, fasting blood glucose levels were significantly $(p<0.01)$ lower and serum insulin levels were significantly $(p<0.01)$ higher in treated diabetic animals $(10.4 \pm 1.0 \mathrm{mmol} / 1$ and $12.8 \pm$ $1.1 \mathrm{\mu U} / \mathrm{ml}$ respectively) compared to untreated diabetic controls $(17.4 \pm 1.7 \mathrm{mmol} / 1$ and $8.0 \pm 0.7 \mu \mathrm{U} / \mathrm{ml}$ respectively). The insulinotropic action of T.crispa was further investigated in vitro using isolated human or rat islets of Langerhans and HIT-T15 cells. In static incubations with rat islets and HITT15 B cells, the extract induced a dosage dependent stimulation and potentiation of basal and glucose-stimulated insulin secretion respectively. This insulinotropic effect was also evi-
\end{abstract}

dent in perifused human and rat islets and HIT-T5 B-cells. The observations that (i) in all three models insulin secretory rates rapidly returned to basal levels on removal of the extract and (ii) in rat islets, a second challenge with $T$. crispa induced an additional, stimulated response, are all consistent with physiological release of insulin by $B$ cells. Moreover, the rate of HIT-T15 glucose utilisation was not affected by incubation with T.crispa, suggesting that the cells were viable throughout. These are the first studies to provide biochemical evidence which substantiates the traditional claims for an oral hypoglycaemic effect of Tinospora crispa, and which also show that the hypoglycaemic effect is associated with increased insulin secretion.

Key words: Tinospora crispa, insulin secretion, hypoglycaemic, insulinotropic.
Diabetes mellitus has been treated orally with herbal remedies based on folk medicine since ancient times. The discovery of insulin in 1921, followed by oral hypoglycaemic drugs (sulphonylureas in 1955 and biguanides a few years later) has rationalised and simplified the treatment of diabetes [1]. Nevertheless, no medicine capable of eliciting a radical cure for diabetes has yet been discovered. Doubts about the efficacy and safety of present day oral hypoglycaemic agents [2-5] have prompted a search for safer and more effective drugs in the treatment of diabetes. Traditional herbal remedies which are naturally free from side effects are still in use by diabetic patients, especially in Third World countries $[6,7]$, and may, therefore, represent new avenues in the search for alternative hypoglycaemic drugs.

In Malaysia, an aqueous extract derived from boiling the stem of a climbing plant, Tinospora crispa (family: Menispermaceae) [8] is taken orally to treat Type 2 (non-insulin-dependent) diabetes and is claimed to be efficacious $[9,10]$. However, to date this claim has not been verified scientifically.

* Present address: Department of Endocrinology, Glaxo Inc., Research Triangle Park, USA
In the present study, we have evaluated T.crispa as a potential source of a specific oral hypoglycaemic agent. We have prepared an aqueous extract derived from a traditional preparation of T.crispa stem which demonstrates significant hypoglycaemic and insulinotropic activity in alloxan-diabetic rats. Moreover, the extract stimulates insulin release from rat islets and HIT-T15 $B$ cells in vitro. It is important to extend such observations to humans, and we also show potent insulinotropic activity of the T.crispa extract in isolated human islets of Langerhans.

\section{Materials and methods}

\section{Preparation of T. crispa extract}

Mature T.crispa stems were obtained from the herb garden of the Universiti Pertanian Malaysia, Serdang, Malaysia. The stems were washed, cut into small pieces, air-dried, ground into powder and boiled and refluxed for $4 \mathrm{~h}$. After centrifugation (40 min, $15000 \mathrm{~g}$, $4^{\circ} \mathrm{C}$ ) to separate the aqueous extract from the solid mass, the supernatant was filtered and freeze-dried. The freeze-dried extract was used in all experiments. 


\section{The effect of T.crispa on the blood glucose and insulin levels of normal and alloxan-diabetic rats}

Male Wistar albino rats (200-300 g) were fasted overnight, then injected intravenously with either an aqueous solution of alloxan monohydrate (Eastman Kodak Co., N Y, USA) at a dose of $40 \mathrm{mg} / \mathrm{kg}$ body weight [11], or $154 \mathrm{mmol} / \mathrm{l} \mathrm{NaCl}$. Diabetic rats with fasting blood glucose levels of $14-20 \mathrm{mmol} / 1$ one week after alloxan administration were selected and divided into two groups. Three weeks after alloxan injection, T.crispa extract $(4 \mathrm{~g} / 1)$ was dissolved in the drinking water of the first group $(n=6)$. Extract administration lasted for two weeks. The diabetic control group $(n=5)$ received normal food and drink. Both groups of animals were allowed food and drink ad libitum and blood glucose (Gilford 3500 analyser, Gilford Instruments Ltd., Middlesex, UK) and insulin (charcoal radioimmunoassay [20]) levels were determined at weekly intervals. The same protocol was used for normal rats after $154 \mathrm{mmol} / 1 \mathrm{NaCl}$ injection.

\section{Islet isolation and tissue culture}

Rat pancreatic islets were prepared by collagenase digestion from fed animals [12]. Isolated islets were collected into tissue culture dishes or $0.45 \mu \mathrm{m}$ Millicell-HA culture inserts (Millipore, Middlesex, UK) using a wire loop under a dissecting microscope. The islets were cultured overnight at $37^{\circ} \mathrm{C}$ in tissue culture medium RPMI 1640 (Gibco Europe, Paisley, UK) supplemented with $10 \%$ (volume/volume) fetal calf serum, streptomycin $(0.1 \mathrm{mg} / \mathrm{ml})$, penicillin $(0.1 \mathrm{mg} / \mathrm{ml})$ and glucose $(11 \mathrm{mmol} / 1)$.

Human islets were isolated from the pancreata of renal transplant donors (with full ethical committee permission) by collagenase digestion [13] and cultured overnight in RPMI 1640. They were then picked into tissue culture inserts (100 islets/insert) and cultured for a further 24-h period prior to perifusion.

\section{Culture of HIT-T15 cells}

HIT-T15 cells were routinely cultured in RPMI 1640 as we have described [14]. The cells were passaged 2-4 days before each experiment and plated in 24-well Nunclon multiwell plates (Gibco Europe, Paisley, UK) or tissue culture inserts at a density of $5 \times 10^{5}$ cells $/$ well (or insert).

\section{Insulin secretion: static incubation}

Batches of 5 rat islets were picked into tubes containing $0.6 \mathrm{ml}$ of a modified Krebs-bicarbonate medium with $20 \mathrm{mmol} / 1$ Hepes $\mathrm{pH} 7.4$ and $2 \mathrm{mg} / \mathrm{ml}$ albumin [14], and additions as listed in the results section. After $2 \mathrm{~h}$ incubation at $37^{\circ} \mathrm{C}$ samples were centrifuged briefly to sediment the islets. The supernatant was diluted in phosphate buffer (40 mmol/l) containing albumin $(1 \mathrm{~g} / 1)$ and merthiolate $(6 \mathrm{mmol} / 1)$, and stored at $-20^{\circ} \mathrm{C}$.

For HIT-T15 cells, the culture medium was aspirated from the multiwells and replaced with modified Krebs-bicarbonate medium containing $5 \mathrm{mg} / \mathrm{ml}$ albumin. After $1 \mathrm{~h}$, this preincubation medium was replaced with buffer containing additions as listed in the results section. After incubation for $1 \mathrm{~h}$, an aliquot was removed, centrifuged briefly to sediment any detached cells, diluted in phosphate buffer and stored at $-20^{\circ} \mathrm{C}$. Insulin release was measured by charcoal radioimmunoassay [15].

\section{Insulin secretion: perifusion}

Tissue culture inserts containing islets or HIT cells were transferred to perifusion chambers and perifused continuously for $1 \mathrm{~h}$ at $37^{\circ} \mathrm{C}$ in basal medium consisting of modified Krebs-bicarbonate buffer with
$2 \mathrm{mmol} / \mathrm{l}$ glucose for islets and no glucose for HIT cells. Samples were collected for insulin assay every $2 \mathrm{~min}$, starting at $50 \mathrm{~min}$. Between 60 and $90 \mathrm{~min}$, the perifusion medium was changed for one supplemented as described in the results section. From $90-110 \mathrm{~min}$, islets or HIT-T15 cells were again perifused with basal medium. The flow rate was $1 \mathrm{ml} / \mathrm{min}$ and the system has a dead-space equivalent to 4-6 min.

\section{Glucose utilisation}

Rates of glucose utilisation were measured as the formation of ${ }^{3} \mathrm{H}_{2} \mathrm{O}$ from $\left[5^{3} \mathrm{H}\right]$ glucose $[16]$. After culture, the medium was removed and replaced by Hepes-buffered bicarbonate medium. This was replaced after $60 \mathrm{~min}$ with medium containing $1 \mu \mathrm{Ci}\left[5-{ }^{3} \mathrm{H}\right]$ glucose $(2$ or $20 \mathrm{mmol} / \mathrm{l}$ ) and additions as listed in the results section. After $1 \mathrm{~h}$ in an atmosphere of humidified air at $37^{\circ} \mathrm{C}, 100 \mu \mathrm{l}$ aliquots were acidified by the addition of $20 \mu \mathrm{l} \mathrm{N} \mathrm{HCl}$ and placed in small tubes inside stoppered scintillation vials containing $0.5 \mathrm{ml} \mathrm{H}_{2} \mathrm{O}$. After equilibration overnight at $37^{\circ} \mathrm{C}$, the ${ }^{3} \mathrm{H}_{2} \mathrm{O}$ recovered in scintillation vials was measured by liquid scintillation spectrometry.

\section{Statistical analysis}

For the in vivo studies, the blood glucose and insulin levels are expressed as mean $\pm \mathrm{SEM}$. The significance of the effects of $T$.crispa extract was evaluated by Student's $t$-test.

We have previously shown that the amount of insulin secreted by HIT-T15 cells varies considerably between passages [14]. Therefore, the following protocol was followed so that data from several experiments could be combined and compared. Each experiment always included 8 control wells containing cells incubated in the absence ( 4 wells) and in the presence of $10 \mathrm{mmol} / 1$ glucose ( 4 wells). Release rates for test conditions were then expressed as a percentage of the mean value of the appropriate control rates in the same experiment and are given throughout as mean \pm SEM. Each test condition was examined in five experiments, with 4 replicates per experiment. The mean absolute control rates of insulin secretion are given for each separate series of experiments. The significance of the effects of T.crispa on HIT-T15 insulin release were assessed using the Student's $t$-test.

A similar protocol was followed for the experiments with isolated rat islets. For the perifusion studies, data from rat islets are presented as mean absolute levels of insulin from three experiments. Data from HIT-T15 cells are, however, presented as a representative of four similar experiments due to the variability in the amount of insulin released by the cells from different passage numbers. Similarly, we have found that individual preparations of human islets are more heterogeneous in terms of islet size, insulin content and absolute levels of insulin released in perifusion. Therefore, insulin secretory data for human islets exposed to either high glucose or T.crispa extract are expressed relative to the basal release of islets from the same individual preparation, and are representative of three separate preparations.

\section{Results}

\section{The effect of T. crispa extract on the blood glucose and insulin levels and weight gains of normal and alloxan-diabetic rats}

Diabetic rats with fasting hyperglycaemia (blood glucose levels of between $14.0-20.0 \mathrm{mmol} / 1$ one week after alloxan injection, were selected for these studies. Figure 1 shows that immediately prior to extract administration, there was no significant difference between 

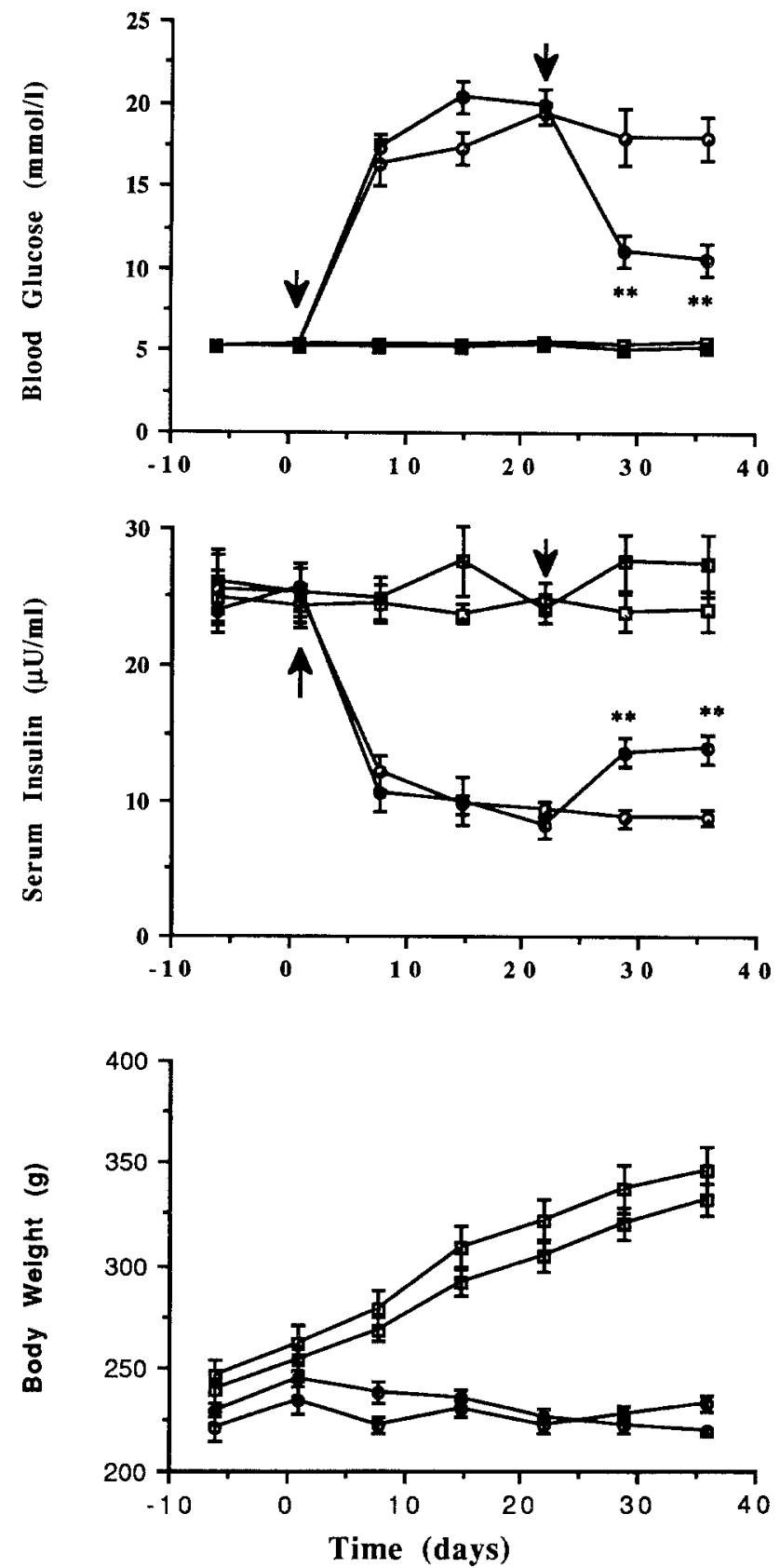

Fig. 1. Hypoglycaemic and insulinotropic effect of T.crispa extract in alloxan-diabetic rats. T. crispa extract was administered 3 weeks after the induction of diabetes with alloxan (day 0). After one week, blood glucose levels of treated diabetic rats (closed circles, $n=6$ ) fell significantly $(p<0.01)$ compared to untreated animals (open circles, $n=5$ ), and remained lower throughout the course of treatment. At the same time, serum insulin levels of treated diabetic rats (closed circles) rose significantly $(p<0.01)$ compared to untreated animals (open circles). The body weight of diabetic animals (closed circles) was higher $(p<0.05)$ two weeks after T.crispa treatment compared to untreated animals (open circles). Data are given as mean $\pm S E M$. In contrast, T.crispa had no significant effect on the parameters measured from normal animals (normal controls: open square; normal treated: closed square)

the blood glucose and insulin levels of the two diabetic groups of animals. However, after only one week, the blood glucose levels of diabetic rats treated with T.cris$p a$ extract were significantly lower than controls

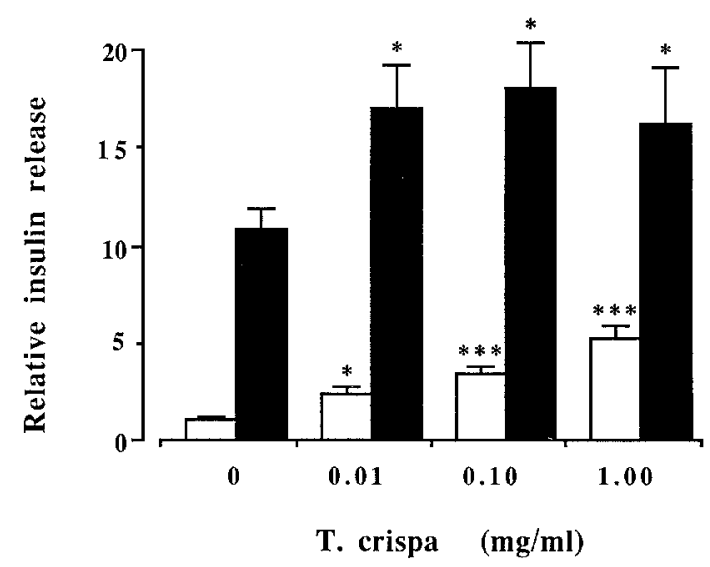

Fig.2. Stimulation of rat islet insulin release by $T$. crispa extract. T.crispa extract induced a dosage dependent initiation of basal ( $2 \mathrm{mmol} / 1$ glucose, open bars) insulin release and also potentiated glucose-stimulated ( $10 \mathrm{mmol} / 1$ glucose, solid bars) secretion. Data are given as mean $\pm S E M$. In these experiments the mean absolute value of basal insulin release was $20.0 \pm 3.3 \mu \mathrm{U} \cdot$ islet $^{-1} \cdot \mathrm{h}^{-1}$. Statistical significances of the observed differences in insulin release compared to the appropriate controls ( 2 or $10 \mathrm{mmol} / 1$ glucose) are: *** $p<0.001$; $* p<0.05$

$10.4 \pm 1.0 \mathrm{mmol} / 1$ vs $17.4 \pm 1.7 \mathrm{mmol} / 1, \mathrm{p}<0.01$ ), and the insulin levels were significantly higher $(12.8 \pm 1.1 \mu \mathrm{U} / \mathrm{ml}$ vs $8.0 \pm 0.7 \mu \mathrm{U} / \mathrm{ml}, \mathrm{p}<0.01)$. Moreover, this hypoglycaemic and insulinotropic effect was maintained throughout the 2-week treatment. In contrast, the plasma glucose and insulin levels of the untreated diabetic rats remained unchanged throughout the experimental period. In contrast to diabetic animals, there was no significant change in blood glucose and insulin levels in normal rats after T.crispa treatment.

Figure 1 also shows that, in contrast to normal rats, the diabetic animals did not gain weight. In fact, there was a slight but significant weight loss three weeks after alloxan administration (from 234.2 \pm 4.1 to $216.8 \pm 3.6 \mathrm{~g}, \quad p<0.05, n=6$ ). Thereafter, T.crispa treated animals showed signs of recovery in body weight gains, reaching statistical significance two weeks after treatment $(227.5 \pm 3.6, n=6)$ compared to diabetic controls $(214.2 \pm 2.1, n=5, p<0.05)$.

\section{The effect of T.crispa extract on insulin release by rat islets}

Figure 2 shows that T.crispa extract in the range $0.01-1.00 \mathrm{mg} / \mathrm{ml}$ induced a dosage dependent initiation of basal ( $2 \mathrm{mmol} / 1$ glucose) insulin release with a maximum 5-fold stimulation. Moreover, over the same range of concentrations, T.crispa potentiated glucose stimulated insulin release 1.5 -fold.

The insulinotropic effect of T.crispa was also evident in the perifusion studies (Fig.3). Incubation of islets with $10 \mathrm{mmol} / 1$ glucose induced stimulation of basal insulin release, the rate of which fell rapidly when 


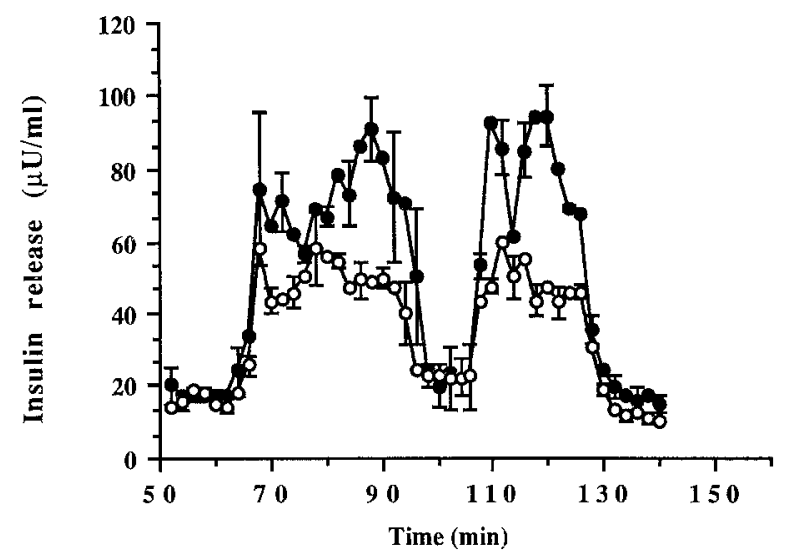

Fig. 3. The effect of $T$. crispa on the insulin secretory dynamics of rat islets. Islets were perifused in basal $(2 \mathrm{mmol} / 1$ glucose $)$ medium for $1 \mathrm{~h}$, and then challenged with either $10 \mathrm{mmol} / /$ glucose (open circles) or $10 \mathrm{mmol} / 1$ glucose plus $0.1 \mathrm{mg} / \mathrm{ml}$ T. crispa extract (closed circles) for $30 \mathrm{~min}$. Next, after an additional $10 \mathrm{~min}$ in basal medium, islets were stimulated again for a further $20 \mathrm{~min}$. Finally, basal conditions were restored for $20 \mathrm{~min}$. The data are presented as mean $\pm \mathrm{SEM}$ of three individual preparations of rat islets

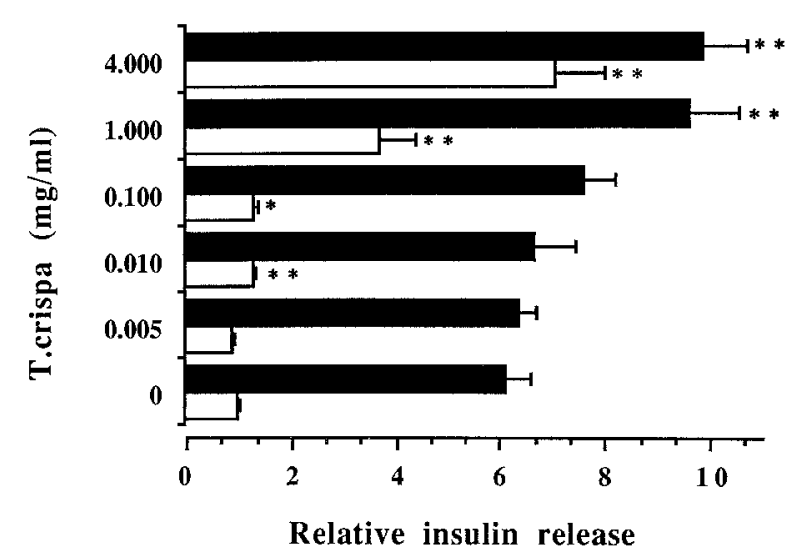

Fig.4. Stimulation of insulin release from HIT-T15 B cells by T. crispa extract. T.crispa extract induced a dosage dependent initiation of basal (open bars) insulin release and also potentiated glucose-stimulated (10 mmol// glucose, solid bars) secretion. Data are given as mean \pm SEM. The mean absolute value of basal insulin release was $177.9 \pm 25.2 \mu \mathrm{U} \cdot \mathrm{ml}^{-1} \cdot \mathrm{h}^{-1}$. Statistical significances of the observed differences in insulin release compared to the appropriate controls ( 2 or $10 \mathrm{mmol} / 1$ glucose) are: ${ }^{* *} p<0.01 ; * p<0.05$

the high glucose medium was replaced by $2 \mathrm{mmol} / \mathrm{l}$ glucose. In addition, on restimulation with $10 \mathrm{mmol} / \mathrm{1}$ glucose, there was a further stimulation of insulin release. The addition of T.crispa extract $(0.10 \mathrm{mg} / \mathrm{ml})$ to high glucose medium resulted in an essentially similar pattern of insulin release, but was characterised by a more marked augmentation of secretion during periods of stimulation.

\section{The effect of T.crispa extract on insulin release by HIT-T15 cells}

Figure 4 shows that, as described above for rat islets, T.crispa induced both a dosage dependent initiation

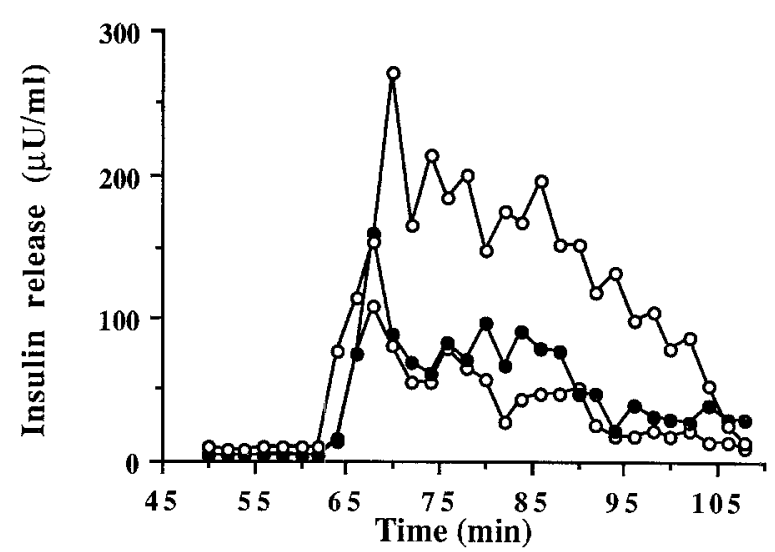

Fig.5. The effect of Tinospora crispa on the insulin secretory dynamics of HIT-T15 B cells. Cells $\left(4 \times 10^{5}-10^{6}\right)$ were perifused in basal medium for $1 \mathrm{~h}$, and then challenged with either $10 \mathrm{mmol} / 1$ glucose (open circles, dotted line), $10 \mathrm{mmol} / 1$ glucose plus $0.1 \mathrm{mg} / \mathrm{ml}$ T.crispa extract (closed circles) or $10 \mathrm{mmol} / 1$ glucose plus $1.0 \mathrm{mg} / \mathrm{ml}$ T.crispa extract (open circles, solid line) for $30 \mathrm{~min}$. After stimulation, basal conditions were restored for $20 \mathrm{~min}$. The data are representative of four similar experiments

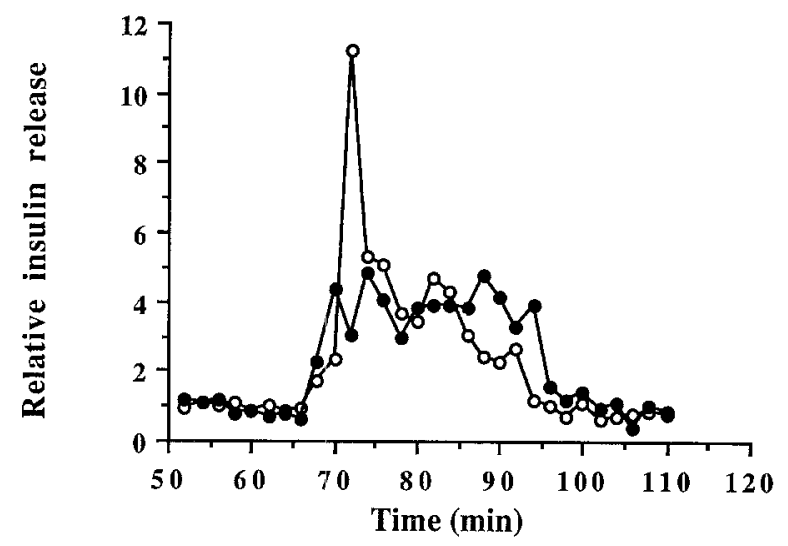

Fig. 6. The insulinotropic effect of T.crispa extract in human islets: stimulation of basal insullin release. 100 islets were perifused in basal medium ( $2 \mathrm{mmol} / 1$ glucose) for $1 \mathrm{~h}$, and then challenged with basal medium supplemented with $1.0 \mathrm{mg} / \mathrm{ml}$ T.crispa extract (closed circles) or with medium containing $10 \mathrm{mmol} / 1$ glucose (open circles), for $30 \mathrm{~min}$. After stimulation, basal conditions were restored for $20 \mathrm{~min}$. The data are representative of three separate preparations of human pancreas

and potentiation of glucose-stimulated insulin release in HIT-T15 cells. In the absence of glucose, T. crispa extract $(0.01-4.00 \mathrm{mg} / \mathrm{ml})$ stimulated basal HIT-T15 insulin release in a dosage dependent manner, with a 7fold elevation of basal levels. Over the same concentration range, glucose-stimulated HIT-T15 insulin release was potentiated up to 1.5 -fold.

When the extracellular glucose concentration was raised from 2 to $20 \mathrm{mmol} / 1$, the rate of HIT-T15 glucose utilisation increased significantly $(p<0.001)$ from $34.0 \pm 1.8(n=6)$ to $66.3 \pm 4.4 \quad(n=6) \quad \mathrm{nmol}$ glucose/well. However, at both 2 and $20 \mathrm{mmol} / \mathrm{l}$ glucose, T.crispa extract $(1 \mathrm{mg} / \mathrm{ml})$ had no significant effect on the rate of glucose utilisation.

In addition, Figure 5 shows that the dosage depend- 


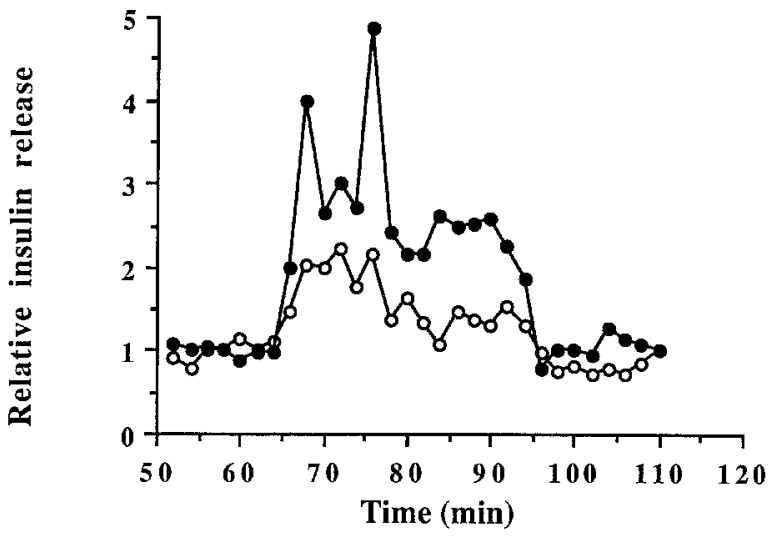

Fig.7. The insulinotropic effect of T. crispa in human islets: potentiation of glucose-stimulated insulin release. Islets were perifused in basal ( $2 \mathrm{mmol} / 1$ glucose) medium for $1 \mathrm{~h}$, and then challenged with medium containing $10 \mathrm{mmol} / 1$ glucose (open circles) or $10 \mathrm{mmol} / 1$ glucose plus $1.0 \mathrm{mg} / \mathrm{ml} \mathrm{T}$. crispa extract (closed circles), as described in the legend to Fig. 6

Table 1. Glucose, total protein and ionic composition of $1 \mathrm{mg} / \mathrm{ml}$ $T$. crispa extract. Data are presented as mean $\pm \mathrm{SEM}, n=3$. Statistical significance of the difference in composition compared to the appropriate control: ${ }^{\mathrm{a}} p<0.05$

\begin{tabular}{lcc}
\hline Component & Hepes-Krebs $(\mathrm{HK})$ & $\mathrm{HK}+1 \mathrm{mg} / \mathrm{ml}$ T.crispa \\
\hline Glucose $(\mathrm{mmol} / \mathrm{l})$ & $<1.0$ & $<1.0$ \\
Total Protein $(\mathrm{g} / \mathrm{l})$ & $5.03 \pm 0.03$ & $5.03 \pm 0.03$ \\
Sodium $(\mathrm{mmol} / \mathrm{l})$ & $135.67 \pm 2.85$ & $135.67 \pm 3.33$ \\
Phosphate $(\mathrm{mmol} / \mathrm{l})$ & $1.29 \pm 0.03$ & $1.52 \pm 0.05^{\mathrm{a}}$ \\
Magnesium $(\mathrm{mmol} / \mathrm{l})$ & $1.23 \pm 0.05$ & $1.35 \pm 0.07$ \\
Calcium $(\mathrm{mmol} / \mathrm{l})$ & $2.70 \pm 0.10$ & $2.75 \pm 0.12$ \\
Potassium $(\mathrm{mmol} / \mathrm{l})$ & $6.10 \pm 0.10$ & $6.57 \pm 0.28$ \\
\hline
\end{tabular}

ent insulinotropic effect of T.crispa was also evident in perifusion studies, and was characterised by the potentiation of both phases of the HIT-T15 insulin secretory response.

\section{The effect of T.crispa extract on insulin release by human islets}

The effect of T.crispa on the insulin secretory responsiveness of isolated human islets is shown in Figures 6 and 7 . High glucose $(20 \mathrm{mmol} / \mathrm{l})$ alone provoked the stimulation of basal insulin release. The addition of $1.00 \mathrm{mg} / \mathrm{ml}$ T. crispa extract to basal medium induced a similar stimulation of insulin secretion to high glucose alone. Moreover, Figure 7 shows that in the human, as in the rodent, T.crispa also potentiated glucose-stimulated insulin release.

\section{Glucose, total protein and ionic composition of $1 \mathrm{mg} / \mathrm{ml} \mathrm{T}$.crispa extract}

Table 1 shows that the composition of Hepes-Krebs medium used in the experiments was not altered by ad- dition of $1 \mathrm{mg} / \mathrm{ml}$ T.crispa except for phosphate content which was higher $(p<0.05, n=3)$ in the medium containing the extract.

\section{Discussion}

It has been estimated that over $25 \%$ of the prescription drugs in the USA contain active ingredients of higher plant origin [17]. However, although numerous plant extracts have been claimed to possess hypoglycaemic activity [18], there have been very few studies of the effects of herbal extracts on insulin secretion and no specific hypoglycaemic agent has yet been identified [6].

In the present study we have investigated the climber Tinospora crispa, an aqueous extract of which has been traditionally used as an oral hypoglycaemic by diabetic patients in Malaysia. First, an aqueous extract of the stem was prepared using a method which essentially followed the traditional preparation and then the putative hypoglycaemic activity was investigated in normal and alloxan-diabetic rats. Since alloxan may cause partial or even total necrosis of islet B cells [19], a submaximal dose was chosen $(40 \mathrm{mg} / \mathrm{kg}$ body weight) to ensure that the animals retained sufficient viable $B$ cells to maintain a moderately hyperglycaemic state (as in Type 2 diabetes). The administration of T. crispa extract to the drinking water of diabetic animals induced a significant hypoglycaemic effect after only one week of treatment. This was associated with a significant increase in the serum insulin levels. Moreover, these effects were maintained throughout the 2-week treatment.

Two weeks after T.crispa treatment, the mean body weight of diabetic animals was significantly higher than that of diabetic controls. Therefore, the possibility that weight loss could ameliorate Type 2 diabetes can be ruled out.

In contrast to diabetic animals, normal rats did not show any significant response to T.crispa treatment. This may be due to the difference in water consumption (thus amount of extract) between normal and diabetic animals. Lazarow and Palay (1946) reported that diabetic rats drank approximately eight times more water than normal rats. Hence, the actual blood concentration of the extract might not have been high enough to stimulate insulin secretion and affect plasma glucose levels in normal animals.

Next, we examined in more detail the potential insulinotropic activity of T.crispa using three in vitro models. T.crispa extract was shown to evoke a dosagedependent stimulation of basal insulin release and also to potentiate glucose-stimulated secretion in rodent models (rat islets, HIT-T15 cells). Moreover, the potent insulinotropic activity of T.crispa was also evident in isolated human islets.

We can also present evidence which demonstrates that the insulin release induced by T.crispa is physiological and does not simply reflect efflux due to toxicity. 
First, in all of the perifusion studies insulin secretory rates rapidly fell to basal levels on removal of the T.crispa stimulus. In addition, in rat islets, a second challenge with T.crispa induced an additional, stimulated secretory response. Moreover, the rate of HIT-T15 glucose utilisation was not affected by incubation with T.crispa, suggesting that the cells were viable throughout the experiment. This latter observation also shows that the insulinotropic activity of T.crispa is not mediated by increased flux through glucose metabolism.

The crude aqueous extract used in these studies is most probably a complex mixture that may contain established insulin secretagogues. Nevertheless, we have been able to show that there were no significant amounts of either glucose or calcium or potassium ions (which in themselves may have been partially responsible for the insulinotropic characteristics) present in the extract at the concentrations used.

In conclusion, these are the first studies to provide biochemical evidence which substantiates the traditional claims for an oral hypoglycaemic effect of Tinospora crispa extract, and which also show that the hypoglycaemic effect is associated with a potent in vitro insulinotropic activity in the human and rat islets and HIT-T15 B cells. Further characterisation of the crude extract may lead to the isolation of a unique oral hypoglycaemic agent for the treatment of Type 2 diabetes.

Acknowledgements. We are grateful to Drs. A.E.Boyd III and R.F. Santerre for supplying us with HIT-T15 cells and to Dr. J. Kay for analysis of the T.crispa extract. H. Noor gratefully acknowledges support from the Government of Malaysia. Financial support for these studies was provided by the British Diabetic Association.

\section{References}

1. Asmal AC, Marble A (1984) The oral hypoglycaemic agents. An update. Drugs 28: 62-78

2. University Group Diabetes Program (1974) A study of the effects of hypoglycaemic agents on vascular complications in patients with adult-onset diabetes: section V. Evaluation of phenformin therapy. Diabetes 24 (Suppl.1): 65-184

3. Knatterud G, Klimt CR, Levin ME, Jacobsen ME, Goldner MG (1978) Effect of hypoglycaemic agents on vascular complications in patients with adult-onset diabetes: section VIII. Mortality and selected nonfatal events with insulin treatment. JAMA $240: 37-42$

4. Reaven GM (1983) Therapeutic approaches to reducing insulin resistance in patients with noninsulin-dependent diabetes mellitus. Am J Med 74: 109-112
5. Jenkins DJA, Wolever TMS, Leeds AR, Gassull MA, Haisman P, Dilawari JB, Goff DV, Metz GL, Alberti KGMM (1978) Dietary fibres, fibre analogues, and glucose tolerance: importance of viscosity. Br Med J 1: 1992-1994

6. Ajgaonkar SS (1979) Herbal drugs in the treatment of diabetes. A review. International Diabetes Federation Bulletin 24: 10-19

7. Weragoda B (1970) Some questions about the future of traditional medicine in developing countries. J Ethnopharmacol 2: 193-194

8. Burkill LH (1966) A dictionary of the economic products of the Malay Peninsula: vol II. Ministry of Agriculture and Cooperations, Kuala Lumpur, pp 2202-2205

9. Hirschhorn HH (1983) Botanical remedies of the former Dutch East Indies (Indonesia). Part II: Dicotyledons up to and including Leguminosae. J Ethnopharmacol 8: 65-96

10. Gimlette JD, Burkill LH, Ismail Munshi (1930) The medicinal book of Malayan Medicine. Gard Bull Str Settle 6: 323-474

11. Lazarow A, Palay SL (1946) The production and course of alloxan diabetes in the rats. J Lab Clin Med 31: 1004

12. Sutton R, Peters M, McShane P, Gray DWR, Morris PJ (1986) An improved method for the isolation of islets of Langerhans from the adult rat pancreas. Transplant Proc 18: 1819-1820

13. Gray DWR, McShane P, Grant AM, Morris PJ (1984) A method for isolation of islets of Langerhans from the human pancreas. Diabetes 33: 1055-1061

14. Ashcroft SJH, Hammonds P, Harrison DE (1986) Insulin secretory responses of a clonal cell line of simian virus 40 -transformed B-cells. Diabetologia 29: 727-733

15. Ashcroft SJH, Crossley JR (1975) Effects of glucose, N-acetylglucosamine, glyceraldehyde and other sugars on insulin release in vivo. Diabetologia 11: 279-284

16. Ashcroft SJH, Weerasinghe LCC, Bassett JM, Randle PJ (1972) The pentose cycle and insulin release in mouse pancreatic islets. Biochem J 126: 525-532

17. Farnsworth NR, Bingel AS (1977) Problems and prospects of discovering new drugs from higher plants by pharmacological screening. In: Wagner $\mathrm{H}$, Wolff $\mathbf{P}$ (eds) New natural products and plant drugs with pharmacological, biological or therapeutic activity. Springer, Berlin Heidelberg New York, pp 1-22

18. Bever BO, Zahnd GR (1979) Plants with oral hypoglycaemic action. Quart J Crude Drug Res 17: 139-196

19. Rerup CC (1970) Drugs producing diabetes through damage of the insulin secreting cells. Pharmacol Rev 22: 485-517

20. Albano JDM, Ekins RP, Maritz G, Turner RC (1972) A sensitive, precise radioimmunoassay of serum insulin relying on charcoal separation of bound and free hormone moieties. Acta Endocrinol 70: 487-509

Received: 6 February 1989

and in revised form: 7 April 1989

\section{H. Noor}

Nuffield Department of Clinical Biochemistry

John Radcliffe Hospital

Headington

Oxford OX3 9DU

UK 